\title{
Extracranial Dural Arteriovenous Fistula as a Cause of Mastoid Mass: A Case Report
}

Michael Gregorio Ortega-Sierra', Juan Alberto Fernández-Lora ${ }^{2}$, Adriana Barrera-Patiño ${ }^{3}$, Miguel Andrés MontalvoClavijo $^{4}$, Gina Paola Montiel-Lombana ${ }^{5}$, Edinson Montero-Cruz ${ }^{6}$, Diana Karina Mena Yi ${ }^{7}$ and Md Moshiur Rahman ${ }^{8 * *}$

${ }^{1}$ School of Medicine, Corporación Universitaria Rafael Nuñez, Cartagena, Colombia

${ }^{2}$ School of Medicine, Universidad del Magdalena, Santa Marta, Colombia

${ }^{3}$ School of Medicine, Universidad del Rosario, Bogotá, Colombia

${ }^{4}$ School of Medicine, Fundación Universitaria Juan N corpas, Bogotá, Colombia

${ }^{5}$ School of Medicine, Universidad de Santander, Bucaramanga, Colombia

${ }^{6}$ School of Medicine, Universidad del Tolima, Ibagué, Colombia

${ }^{7}$ School of Medicine, Universidad de Cartagena, Cartagena, Colombia

${ }^{8}$ Neurosurgery Department, Holy Family Red Crescent Medical College, Dhaka, Bangladesh

*Corresponding author: Rahman M, Assistant Professor, Neurosurgery Department, Holy Family Red Crescent Medical College, Dhaka, Bangladesh

Received date: 15 November, $2021 \mid$

Accepted date: 25 November, $2021 \mid$

Published date: 28 November, 2021

Citation: Ortega-Sierra MG, Fernandez-Lora JA, Barrera-Patino A, Montalvo-Clavijo MA, Montiel-Lombana GP, et al. (2021) Extracranial Dural Arteriovenous Fistula as a Cause of Mastoid Mass: A Case Report. J Anaesth Anesth Drug 1(1). doi https://doi.org/ 10.54289/JAAD2100105

Copyright: @ 2021 Ortega-Sierra MG, et al. This is an open-access article distributed under the terms of the Creative Commons Attribution License, which permits unrestricted use, distribution, and reproduction in any medium, provided the original author and source are credited.

\section{Abstract:}

Introduction: Dural arteriovenous fistulas account for 10 to $15 \%$ of intracranial arteriovenous malformations. They are defined as malformations to short-circuits between dural and extracranial arteries with dural venous sinuses. Its presentation is in frequent and its management is a challenge in low- and middle-income countries where there are difficulties in accessing high quality technological tools.

Case: We present the case of an unusual dural arteriovenous fistula involving the mastoid region and draining into the external jugular vein and through emissary veins into the superior longitudinal sinus, which was treated transarterially.

Conclusion: Endovascular management of intracranial dural arteriovenous fistulas can be a challenge. Endovascular treatment includes a transarterial or transvenous approach from the femoral artery or vein. There is little evidence on this subject, so it is necessary to carry out more studies to determine risk factors, intervention effects and medium- and long-term outcomes.

Key words: Endovascular Procedures, Arteriovenous Fistula, Extracranial Dural Fistula, Neurosurgery, Case Report

\section{Introduction}

Dural arteriovenous fistulas account for 10 to $15 \%$ of intracranial arteriovenous malformations [1,2]. They are defined as malformations to short-circuits between dural and extracranial arteries with dural venous sinuses [1,2]. Its etiology is still unknown. However, they have been associated with conditions such as trauma, post-surgery, venous stenosis or sinus thrombosis [3-5]. Although the vast majority are benign in course, they represent a risk due to the possibility of retrograde venous drainage and cortical venous reflux, generating vascular failure that can trigger hemorrhage, neurological injury, disability and death $[4,5]$. Treatment selection depends on variables such as fistula architecture, location and direction of venous flow. 
Endovascular management is recommended [5]. However, in non-specialized centers where there are no endovascular management units, it is a challenge to perform definitive correction of this lesion. Low- and middle-income countries suffer from this type of difficulties.

The aim of this manuscript is to present a case of an unusual dural arteriovenous fistula involving the mastoid region and draining into the external jugular vein and through emissary veins into the superior longitudinal sinus, And discuss aspects related to the limitations in the diagnosis and approach in lowand middle-income countries such as Colombia

\section{Case description}

50-year-old female, secretary, presented to the emergency department with a clinical picture of approximately pulsatile tinnitus and increasing progress of a mass in the retroauricular region. No relevant personal or family history. She presented with pain on pressure. Cranial CT angiography showed evidence of extracranial fistula. Diagnostic angiography revealed an extracranial dural arteriovenous fistula dependent on the right external carotid artery (Figures 1 a,b). By means of conventional endovascular technique, transfemoral embolization of the fistula was performed. Angiographic occlusion of the malformation was achieved. A 3-month follow-up was performed, where a satisfactory evolution and complete resolution of the clinical picture was observed.

\section{Discussion}

Regarding extracranial dural fistulas, there is not much scientific literature, and if there is, it is limited to case series and case reports [6-10]. However, among the few reported cases, Yu et al [6] present a case of trauma with fistula formation between the middle meningeal artery and pterygoid plexus in an 8-year-old pediatric patient with a history of fall and head trauma

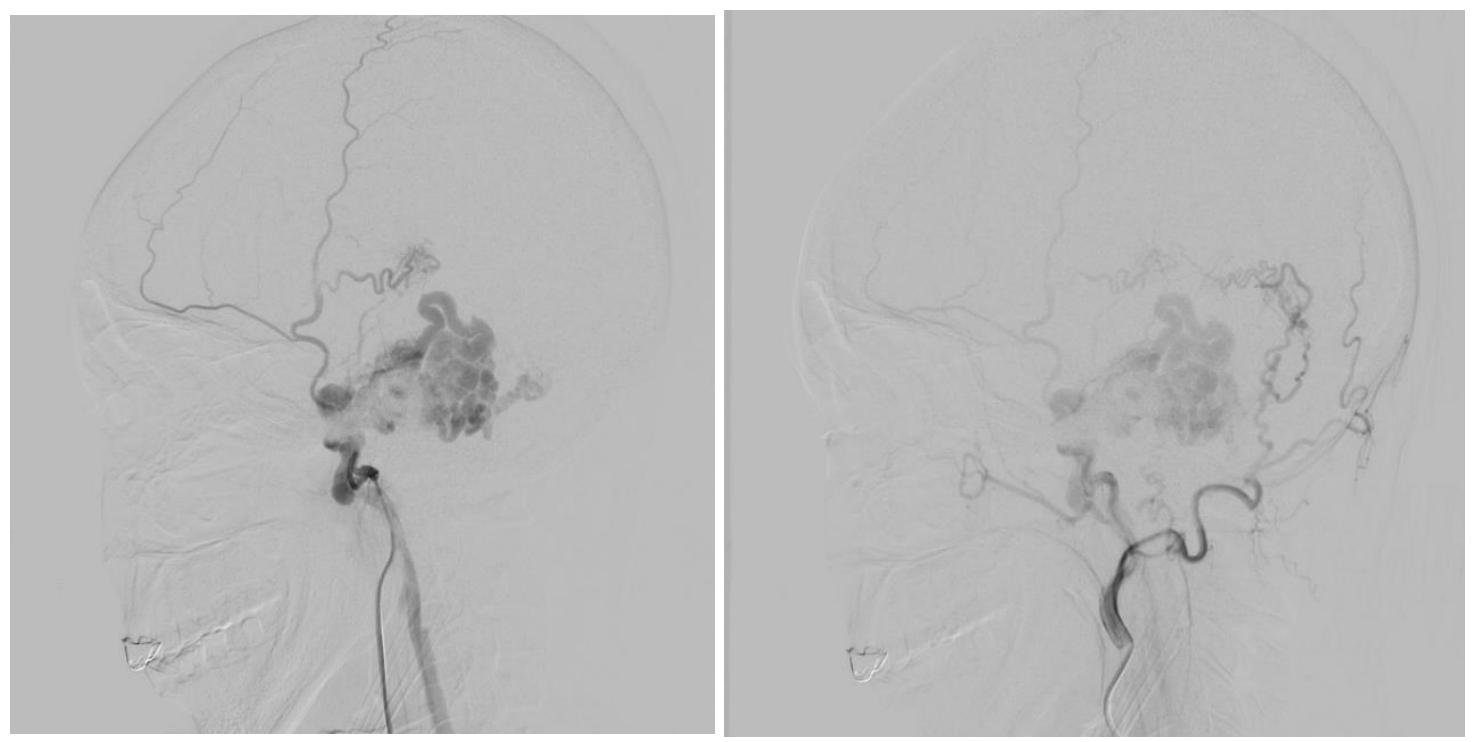

Figure 1 (a,b). Computed tomography angiography showing evidence of an extracranial dural arteriovenous fistula located in the right mastoid region.

at 4 months of age. The patient developed exophthalmos in the left eye and conjunctival redness. When auscultating the left region of the face, an intracranial murmur was evidenced at the level of the temporal region (aspect to note that should be performed during the physical examination). Endovascular management was performed with subsequent resolution [6]. In the 1980s, a case of spontaneous vertebral arteriovenous fistula associated with fibromuscular dysplasia was reported, which triggered cervical myelopathy, postulating fibromuscular alterations as a potential risk factor [7].
On the other hand, Buschmann et al [9] carried out a study in a biological pig model, with the aim of identifying compounds related to extracranial arteriogenesis in the development of fistulas, finding that proteins such as CD44, MCP-1 and TIMP-1 are overexpressed and are directly related to the pathophysiological process, especially postintervention [9]. In addition, they showed that high flow increases the speed of cell proliferation and invasion by monocytes. This allowed the authors to conclude that vascular remodeling is an active process that is self-regulating 
in the first 15 days post-intervention [9], and that due to the increase in cell proliferation due to the activity of proangiogenic factors, endovascular management should be carried out rapidly once the diagnosis is made Although the evidence is limited, it is evident that endovascular management should be performed to ensure a safe and effective outcome. However, looking at the case of Bárcena Orbe et al [10], it can also be presumed that in surgeries that are high risk and are very invasive, it should always be taken into account that the development of fistula as a potential complication [10]. There are systematic reviews on intracranial dural fistulas, but nothing related to extracranial fistulas $[\mathbf{1 1 , 1 2}]$. It is necessary to reinforce the infrastructure, funding and training in robotic neurosurgery and endovascular management in low- and middle-income countries, with the aim of producing better quality evidence to fully understand the behavior of this type of conditions and their long-term evolution [13-15].

\section{Conclusión}

Endovascular management of intracranial dural arteriovenous fistulas can be a challenge. Endovascular treatment includes a transarterial or transvenous approach from the femoral artery or vein. There is little evidence on this subject, so it is necessary to carry out more studies to determine risk factors, intervention effects and medium and long term outcomes.

\section{References}

1. Padget DH. (1948) The development of the cranial arteries in the human embryo. Contrib Embryol. 32: 205-262.

2. Ziyeh S, Schumacher M, Strecker R, Rössler J, Hochmuth A, et al. (2003) Head and neck vascular malformations: timeresolved MR projection angiography. Neuroradiology. 45(10): 681-686.

3. San Millán Ruíz D, Gailloud P, Rüfenacht DA, Delavelle J, et al. (2002) The craniocervical venous system in relation to cerebral venous drainage. AJNR Am J Neuroradiol. 23(9): 1500-1508.

4. Kiyosue H, Okahara M, Sagara Y, Tanoue S, Ueda S, et al. (2007) Dural arteriovenous fistula involving the posterior condylar canal. AJNR Am J Neuroradiol. 28(8): 1599-1601.

5. Reynolds MR, Lanzino G, Zipfel GJ. (2017) Intracranial

Dural Arteriovenous Fistulae. Stroke. 48(5): 1424-1431.
6. Yu J, Guo Y, Wu Z, Xu K. (2017) Traumatic arteriovenous fistula between the extracranial middle meningeal artery and the pterygoid plexus: A case report and literature review. Interv Neuroradiol. 23(1): 90-96.

7. Reddy SV, Karnes WE, Earnest F 4th, Sundt TM Jr. (1981) Spontaneous extracranial vertebral arteriovenous fistula with fibromuscular dysplasia. Case report. J Neurosurg. 54(3): $399-402$.

8. Maus V, Söderman M, Rodesch G, Kabbasch C, Mpotsaris A. (2017) Endovascular treatment of posterior condylar canal dural arteriovenous fistula. J Neurointerv Surg. 9(2): e7.

9. Buschmann EE, Lee EJ, Jacobi D, Woischnig AK, Ulusans $\mathrm{S}$, et al. (2018) Induction of extracranial arteriogenesis by an arteriovenous fistula in a pig model. Atherosclerosis. 272: 8793.

10. Bárcena Orbe J, Rodríguez Hernández C, Mestre Moreiro JM, Cañizal García B, Rivero Martín. (1994) Fístula arteriovenosa extracraneal secundaria a microcompresión percutánea del ganglio de Gasser. Neurocirugia. 5(3): 259261.

11. Spittau B, Millán DS, El-Sherifi S, Hader C, Singh TP, et al. (2015) Dural arteriovenous fistulas of the hypoglossal canal: systematic review on imaging anatomy, clinical findings, and endovascular management. J Neurosurg. 122(4): 883-903.

12. Baharvahdat H, Ooi YC, Kim WJ, Mowla A, Coon AL, et al. (2020) Updates in the management of cranial dural arteriovenous fistula. Stroke Vasc Neurol. 5(1): 50-58.

13. Blanco-Teherán C, Quintana-Pájaro L, Narvaez-Rojas A, Martínez-Pérez R, García-Ballestas E, et al. (2021) Evidencebased medicine in neurosurgery: why and how? J Neurosurg Sci. 2021 Aug 3.

14. Lozada-Martínez I, Maiguel-Lapeira J, Torres-Llinás D, Moscote-Salazar L, Rahman MM, et al. (2021) Letter: Need and Impact of the Development of Robotic Neurosurgery in Latin America. Neurosurgery. 88(6): E580-E581.

15. Pérez-Fontalvo NM, De Arco-Aragón MA, JimenezGarcía JDC, Lozada-Martinez ID. (2021) Molecular and computational research in low- and middle-income countries: Development is close at hand. J Taibah Univ Med Sci. 16(6):948-949.

ACQUIRE PUBLICATIONS Volume 1 Issue 1 